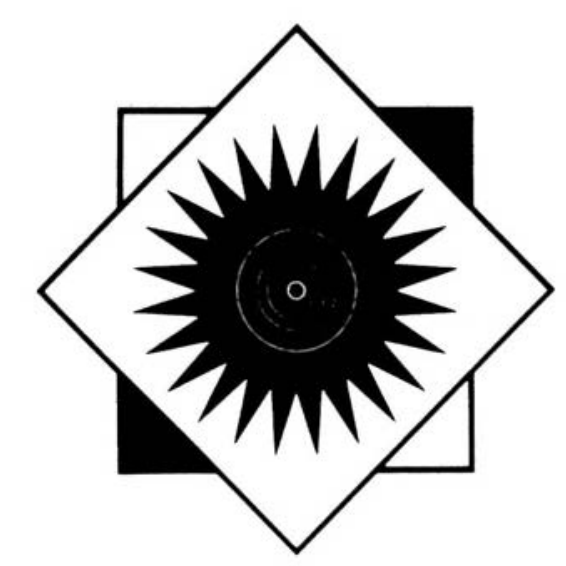

\title{
INNOVATIONS
}

\section{Creativity in an urban university library}

\author{
By Hannelore B. Rader
}

Director of Libraries

Cleveland State University

I applaud Joanne Euster for initiating a $C \triangleleft R L$ News column on "Innovations." Using creative approaches to problem-solving in an academic library setting is an idea whose time has come. With newly-developed technologies helping us to improve library work and services, innovative solutions to problems are a must because traditional models are no longer effective.

Creative managers can guide their staffs toward a path of innovative problem-solving and prepare them for the risk-taking implied in that. Such managers must be able to assess traditional situations with a view to the future and initiate appropriate changes. They must become change agents within their library and role models for their staffs. They must be able to seize opportunities at any given moment and develop them in innovative ways for the express purpose of providing users with the best and most effective library service. Creative managers will approach situations positively and will be successful in taking advantage of opportunities whenever they present themselves.

At Cleveland State University we are beginning to approach problem-solving creatively. A new organizational structure of the library is being implemented which features a blending of services and a softening of area demarcations in view of automation. Major departments will be collection development, processing, reference, and document delivery with staff responsibility crossovers. Middle managers will function in a participatory environment which utilizes task forces and other action groups to address problems and issues in creative ways.

A new Office of Library Studies and Research is being established with an ambitious agenda. This office will provide grant support for the library; bibliographic research support for grant-related and special faculty projects; research help for the campus development office; statistical development for the library, evaluation studies of library services and collections, and so on. It will be staffed by the most experienced senior library faculty member.

New relationships and services are being developed with the urban community to help the campus with recruitment and retention of minorities. Library internship for high school students and an innovative reference assistant program are but the beginnings of that endeavor. The library will play a more active role in supporting such campus concerns.

We are taking some risks as we are embarking upon new endeavors. A contract with General Electric has just been signed to provide library services for their research facility. Although this promises to be an exciting venture for both parties involved, many details will need to be worked out and adjustments will need to be made during the first year.

Overall, it seems that our agenda for innovative services and projects is growing at an accelerated pace. New opportunities are presenting themselves faster than we are able to deal with them. Once an organization decides to "go creative" and people understand what that means, there are virtually no limits for growth and success.

\section{Popular culture papers sought}

The Popular Culture Association will be meeting in New Orleans, March 23-26, 1988. Scholars with an interest in popular culture meet and share common interests. Anyone who is interested in presenting a paper on a topic related to popular culture and libraries should write by November 15, 1987, to: Barbara B. Moran, School of Library Science, University of North Carolina at Chapel Hill, Chapel Hill, NC 27514. 